\title{
Türkiye Cumhuriyet Merkez Bankası (TCMB) Kütüphanesi*
}

\author{
Central Bank of the Republic of Turkey (CBRT) Library
}

\begin{abstract}
Hülya CAN**
Öz

Makalede, Türkiye Cumhuriyet Merkez Bankası Kütüphanesi'nin bugüne kadar geçirdiği aşamalar ve bugün sağlamakta olduğu hizmetler hakkında bilgi verilmiştir.

Anahtar s zc kler: TCMB Kütüphanesi, Özel kütüphaneler, Araştırma kütüphaneleri, Kütüphane tanıtımı, Kütüphane hizmetleri.
\end{abstract}

\begin{abstract}
The paper informs, in detail, the development of the Library of Central Bank of the Republic of Turkey (CBRT) until the present, and explains the services being provided.

Keywords: CBRT Library, Special libraries, Research libraries, Library publicity, Library services.
\end{abstract}

\section{Giriş}

Türkiye Cumhuriyet Merkez Bankası 11 Haziran 1930 tarih ve 1715 sayılı Kanun ile 15 milyon sermayeli bir anonim şirket olarak kurulmuştur. Bu Kanunla Merkez Bankası'na 30 yıllık süre için banknot ihraç etme yetkisi verilmiştir. 3 Ekim 1931 tarihinde Ulus semtindeki Ziraat Bankası binasında faaliyete geçen, 1933 yılında günümüzde Ankara Şubesi olarak kullanılan binaya taşınan Merkez Bankası'nın, banknot ihraç imtiyazı 1955 yılında 1999 yılına kadar uzatılmış, 1994 yılında ise bu imtiyaz süresiz olarak uzatılmıştır (Türkiye Cumhuriyet Merkez Bankası [TCMB], 1996; 2005a).

\footnotetext{
* Kütüphane, Bilgi ve Belge Müdürlüğ̈̈ adı altında hizmet vermekle birlikte, yaygın kullanım dikkate alınarak yazıda "kütüphane" biçiminde ifade edilmiştir.

** Müdür Yardımcısı; TCMB Araştırma ve Para Politikası Genel Müdürlügü Bilgi ve Belge Müdürlügü TCMB Idare Merkezi Ulus 06100 Ankara (Hulya.Can@tcmb.gov.tr).
} 
Merkez Bankası 1930 yılında kurulduğunda temel amacı, ülkenin ekonomik kalkınmasına yardımcı olmak, bu amaçla reeskont oranlarını belirlemek ve para piyasasını düzenlemek, hazine işlemlerini yapmak ve Türk parasının değerini korumak için hükümetle birlikte önlem almak olarak belirlenmiştir.

1715 sayılı kanunda zaman içinde yapılan değişiklikler nedeniyle Bankanın temel işlevi, etkin bir para politikası yürütmekten çok kamu kesiminin finansman açığını kapatmaya yöneldiğinden 26 Ocak 1970 tarih ve 1211 sayılı Kanun ile Merkez Bankası'nın görev ve yetkileri yeniden düzenlenmiştir. 1211 sayılı Kanunda değişiklik yapılmasına dair 25 Nisan 2001 tarih ve 4651 sayılı Kanun ile, hızla değişen ekonomik koşullar ve merkez bankacılığı konusunda, başta Avrupa Birliği normları olmak üzere dünyada meydana gelen gelişmeler çerçevesinde yenilikler getirilmiştir. Bunlardan en önemlisi de Merkez Bankası'nın bağımsızlığının sağlanması, bu kapsamda Hazineye ve kamu sektörüne avans ve kredi verilmesi uygulamasının kaldırılmasıdır. Bu Kanunla Merkez Bankası'nın temel amacının fiyat istikrarını sağlamak ve sürdürmek olduğu ifade edilmiş ve bu kapsamda para politikası araçlarını doğrudan belirlemek ve uygulamakla yetkili ve sorumlu kılınmıştır (Kayaalp, 2001).

Merkez Bankasının Ankara'daki İdare Merkezi dışında 21 ilde şubesi ve 4 ülkede yurt dışı temsilciliği bulunmaktadır.

Merkez Bankası Ocak 1995'ten itibaren internet ortamında veri sunmaya başlamıştır." Web sitesi aracılığıyla Banka ile ilgili tanıııcı bilgilerin yanı sıra, Bankanın duyuruları ile yayınlarına, raporlarına ve ekonomik verilere erişilebilmektedir. 'Siteye üyelik' sayfasından ulaşılabilen abonelik sistemi aracılığıyla Bankanın yayınlarına e-posta yoluyla abone olmak mümkündür. Abone olunan yayınların bildirim sıklığı anlık, günlük ya da haftalık olarak düzenlenmiştir (TCMB, 2005b).

\section{TCMB Kütüphanesi}

Kütüphane ve Dokümantasyon Müdürlüğü adı altında hizmet vermekte iken Temmuz 2005'ten itibaren birimin adı Bilgi ve Belge Müdürlüğü olarak değiştirilmiştir. Araştırma ve Para Politikası Genel Müdürlüğüne bağlı olarak hizmet vermektedir.

Kütüphanenin ne zaman kurulduğu hakkında kesin bir bilgimiz olmamakla birlikte 1970'li yıllarda, Bankanın bugün Ankara Şubesi olarak kullanılan binasında, o zamanki Etüt Müdürlüğüne bağlı bir servis olarak büyük bir odada hizmet verildiği, daha sonra yer darlığı nedeniyle İdare Merkezinin bir

\footnotetext{
${ }^{*}$ TCMB web adresi: http://www.tcmb.gov.tr
} 
bölümü Ulus'taki 100. Yıl binasına taşındığında, kütüphanenin bir kısmının da bu binada iki odaya yerleştirildiği ve zaman zaman 1-2 kütüphanecinin görev yaptığı tarafımızca bilinmektedir. Bankanın 1988 yıında şimdiki binasına taşınması ile birlikte, 17 katı İdare Merkezi binasının 16. katı tamamen kütüphane olarak düzenlenmiştir. Binanın planı gereği iki ayrı salonda hizmet verilmektedir. Salonlardan birinde kitaplar ve danışma kaynakları, diğerinde süreli yayınlar bulunmaktadır. Kitaplar konularına göre, süreli yayınlar yayın adı veya ülke/kurum adı dikkate alınarak alfabetik düzende açık raflara yerleştirilmiştir.

1988 yılında deneyimli bir kütüphaneci, kütüphane müdürü olarak atanmış, yeniden yapılanma çerçevesinde 1989 yılında açılan sınav ile çeşitli servislerde çalıştırılmak üzere beş kütüphaneci ve müdür yardımcısı olarak da bir kütüphaneci alınmıştır. Oluşturulan yeni ekiple mevcut koleksiyon tümüyle elden geçirilmiş ve günlük hizmetler aksatılmadan yeniden düzenlenmiştir. Bu dönemde Kütüphanenin amaç ve görevleri ile hizmet biçimlerini belirleyen bir yönetmelik çıkarılmış, yoğun bir şekilde yayın alımı gerçekleştirilmiş, koleksiyon hizmete uygun şekilde geliştirilmiş ve böylelikle Kütüphanede ilk olumlu dönüşüm yaşanmıştır. İkinci dönüşüm ileride ele alacağımız, otomasyona geçiş ve elektronik erişimler ile gerçekleştirilmiştir.

\section{Amaç}

Kütüphanenin amacı "Bankanın işlevleri doğrultusunda hizmet veren mensuplarının çalışmalarında daha verimli olmalarını sağlamak ve genel kültürlerini geliştirmek için gereksinim duydukları bilgi/belge taleplerini karşılamak ve çağdaş kütüphane/enformasyon hizmeti sunmaktır" (Kütüphane Yönetmeliği, 1997).

\section{Personel}

Kütüphanede bir müdür, bir müdür yardımcısı (kütüphaneci), yayın sağlama hizmetleri için bir kütüphane uzmanı ve bir kütüphaneci ile Bankanın idari kadrolarından bir uzman ve bir şef yardımcısı, kataloglama-sınıflama hizmetleri için bir kütüphaneci, kullanıc hizmetleri için bir kütüphane uzmanı, iki kütüphane uzman yardımcısı ve bir şef, diğer hizmetler için bir memur ve iki evrak memuru olmak üzere toplam 14 kişi görev yapmaktadır.

Kütüphanenin personel yapısı 1997 yılında çıkarılan 2. Kütüphane Yönetmeliği ile oluşturulmuştur. Bu Yönetmelikle kütüphaneci, kütüphane uzman yardımcısı ve kütüphane uzmanı unvanları belirlenmiş, sınavla alınacak kütüphanecilerin, üniversitelerin 4 yıllık eğitim veren kütüphanecilik, enformasyon ve dokümantasyon bölümlerinden mezun olmaları şartı getiril- 
miştir. Kütüphaneci olarak göreve başlayanlar Bankadaki 3 yıllık hizmet süresi sonunda kütüphane uzman yardımcısı, bu unvanda 3 yıl fiilen çalışmış olanlar da kütüphane uzmanı olabilmektedir. Kütüphane uzman yardımcısı ya da kütüphane uzmanı olanlar bir idari kadroya atanabilmektedir.

\section{Koleksiyon}

Kütüphanenin koleksiyonunu ağırlıklı olarak; genel ekonomi, finans, bankacılık konularındaki kitaplar, bilimsel ve aktüel dergiler, danışma kaynakları ile bu alandaki yerli ve yabancı önemli kuruluşlar tarafından yayımlanan tartışma ve çalışma tebliğleri gibi seri yayınlar, başka ülkelerin merkez bankalarının raporları, DPT, DiE, Hazine Müsteşarlığı, Maliye Bakanlığı, SPK, IMKB gibi kuruluşlar ile IMF, Dünya Bankası, OECD, Birleşmiş Milletler, BIS (Bank for International Settlements) gibi önemli uluslararası kuruluşların yayınları, Türkiye Cumhuriyet Merkez Bankasının yayınları ve CD-ROM veri tabanları oluşturmaktadır. Bunların yanı sıra kütüphanede psikoloji, felsefe, sosyoloji, sanat, tarih ile ilgili kitaplar ve bir dönem alınmış olan edebi eserler, günlük gazete ve aktüel dergiler, 1930 yılından bu yana Resmi Gazete koleksiyonda yer almaktadır. Kütüphanede çok eski yıllardan kalmış olan, kayıtsız Arap harfli basma eserler de (başlık olarak 116 adet) bibliyografik kimlikleri tespit edilerek ayrı bir yerde hizmete sunulmuştur.

Kütüphanede başlık olarak 10.541 kitap, 11.077 tartışma ve çalışma tebliği, 1100 adet süreli yayın mevcuttur. 150 adedi yurt dışından, 108 adedi yurt içinden olmak üzere 258 süreli yayın, satın alma yoluyla sağlanmaktadır.

Mevcut CD-ROM veri tabanları şunlardır: Econlit, Ekonomi Ansiklopedisi (Metropol Multimedia), Encyclopedia Britannica, IMF Balance of Payments Statistics, IMF Government Finance Statistics, IMF Direction of Trade Statistics, IMF International Financial Statistics, Iktisat Işletme ve Finans (1997-2001), Vergi Dünyası (1981-2002), Verimlilik Dergisi (1995-2001), World Bank World Data (1995).

Bazı elektronik veri tabanlarına da erişim sağlanmaktadır. Bunlar: $\mathrm{ABI}$ Inform Global, Bankers' Almanac, Business Source Corporate, Cambridge Journals Online, Ebrary elektronik kitap veri tabanı, ECONbase, Economist Intelligence Unit (EIU) Viewswire, Eurostat tarafından üretilen tüm veri ve yayınlara erişim sağlayan European Data Service (EDS), IMF International Financial Statistics, Lebib Yalkın Mevzuat Bankası, OECD tarafından yayımlanan tüm yayınlara ve belgelere erişim sağlayan OLISnet, RGE Monitor, Swetswise, Dünya Bankasının tüm yayınlarına tam metin erişim sağlayan World Bank E-Library, World Bank Global Development Finance, World Bank World Development Indicators. 


\section{Yayın Sağlama}

Yayınlar satın alma ve bağış yoluyla sağlanmaktadır. Kütüphane ile Bankanın diğer birimleri için satın alınacak ya da abone olunacak basılı veya elektronik her türlü yayının satın alınmasına/abone olunmasına Yayın Sağlama Komisyonu tarafından karar verilir. Yayın Sağlama Komisyonu, Bilgi ve Belge Müdürü ve bağlı olduğu birimin Genel Müdürü ile bir ekonomist ve Bankanın üç biriminin Genel Müdüründen oluşur. Bilgi ve Belge Müdürlüğü (Kütüphane) bu Komisyonun sekreterya görevini yürütmektedir. Bankanın birimleri, kendileri ya da Kütüphane için temin edilmesini istedikleri yayınları Araştırma ve Para Politikası Genel Müdürlüğüne resmi olarak bildirirler. Ayrıca Kütüphane tarafından, bağlı olduğu Genel Müdürlükte çalışan araştırmacı ve ekonomistlere yeni yayın katalogları iletilir. Konu uzmanlarının, Kütüphaneye alınmak üzere bu kataloglardan seçtikleri veya kendi araştırmaları ile tespit ettikleri yayınlar ile kütüphane tarafından önerilen yayınlar, diğer birimlerden gelen taleplerle birlikte en az ayda bir kez toplanan Yayın Sağlama Komisyonuna sunulur. Komisyon tarafından satın alınmasına/abone olunmasına karar verilen yayınları sağlamak ve dağııımını yapmak Kütüphanenin görevidir. Bankanın yayın bütçesi Kütüphane tarafından hazırlanır. Yayın alımı konusunda parasal olarak herhangi bir sorun yaşanmamaktadır.

\section{Kataloglama-Sınıflama}

Kitapların kataloglama işlemleri Anglo-Amerikan Kataloglama Kurallarına, sınıflama işlemleri de Dewey Onlu Sınıflama Sistemine göre yapılmaktadır. Konu başlıkları için Kongre Kütüphanesi Konu Başlıkları Listesi kullanılmaktadır. Tartışma tebliği türü yayınlar da kitap gibi kataloglanmakta, konu numarası yerine Kütüphane tarafından belirlenen alfabetik kodlama sistemine göre verilmiş kodlarla nitelenmekte ve süreli yayınlar salonunda hizmete sunulmaktadır.

Yayınların katalog bilgileri kütüphane otomasyon sistemi BLISS-PC'ye, MARC formatında kaydedilmektedir.

\section{Kullanıcı Hizmetleri}

Kütüphaneden Merkez Bankası çalışanları, sosyal bilimler alanında yüksek lisans veya doktora yapan öğrenciler ile tez çalışması yapanlar, akademik personel ile çeşitli kurumlarda uzman veya araştırmacı olarak çalışanlar yararlanabilir. Kütüphane, Bankanın çalışma saatleri içinde ve öğle tatilinde hizmete açıktır.

ÿ Ödünç verme: Merkez Bankası çalışanlarına kitaplar bir ay, süreli yayınlar beş gün süre ile ödünç verilir. Bir kullanıcının üzerinde 
bulunduracağı yayın sayısı 15 adet ile sınırlandırıımıştır. Süreli yayınların son sayıları ile danışma kaynakları ödünç verilmez. Banka dışından gelen kullanıcılara yayın ödünç verilmemekte, bu kullanıcılara belli sayfaya kadar ücretsiz fotokopi hizmeti sunulmaktadır.

ÿ Kütüphaneler arası işbirliği: Kütüphane bilgi/belge sağlama hizmetlerinin hızlı ve ekonomik olarak sunulması amacıyla Ankara içindeki diğer kütüphanelerle işbirliği yapar, kaynak ödünç alır-verir. Diğer kütüphanelere bir seferde en fazla üç belge bir hafta süre ile ödünç verilir.

$\ddot{y} \quad$ Duyuru hizmetleri: Kütüphaneye son gelen yayınlar her ay Bankanın yerel ağı üzerinden ve Kütüphanenin web sayfasından duyurulmaktadır. Deneme erişimli veri tabanları, Kütüphanenin yeni abone olduğu veri tabanları, erişim sağlanabilen elektronik yayınlar ve bunların erişim yolları da yerel ağdan duyurulmaktadır. Ayrıca Banka içinde seçimli bilgi hizmeti ve güncel duyuru hizmeti de verilmektedir.

ÿ Makale veri tabanı: Ekonomi alanında Türkiye'de yayımlanan bilimsel dergilerdeki makaleler indekslenmekte varsa özleri ile birlikte makale veri tabanına kaydedilmektedir. Bu veri tabanı Kütüphane web sayfasında araştırmacıların hizmetine sunulmuştur.

$\ddot{y}$ Kütüphane tanıtımı: Bankanın tüm birimlerine yeni başlayan elemanlar, İnsan Kaynakları Genel Müdürlüğünce bir ön eğitime tabi tutulmakta, Bankanın işlevleri ve birimlerin görevleri hakkında bilgilendirilmektedir. Bu çerçevede Kütüphaneye de yönlendirilen bu kişilere kütüphane hizmetleri ve yararlanma yolları konusunda bilgi verilmekte, tanıtım yapılmaktadır.

ÿ E-posta yoluyla bilgi hizmeti: E-posta yoluyla Kütüphaneye ve Bilgi Edinme Hakkı kapsamında Merkez Bankası İletişim Genel Müdürlüğüne iletilen kullanıcı sorularına, kullanıcıyı ilgili kaynaklara yönlendirmek suretiyle, en kısa sürede cevap verilmektedir.

\section{Kütüphane Otomasyonu}

Bilkent Üniversitesi Bilgi İşlem Birimi tarafından geliştirilen BLISS-PC'nin 1997 yılında satın alınması ile birlikte, kütüphaneye yeni sağlanan kitap ve tartışma tebliği türü yayınların katalog bilgileri sisteme girilmeye başlanmış, bir yandan mevcut kitapların kart katalogdaki kayıtları tek tek veri tabanına aktarılmıştır. Sisteme girilen kitapların barkod etiketleri de tamamlanarak 2000 yılından itibaren kitap salonunda, ödünç verme işlemleri sistemden yapılmaya başlanmıştır. Süreli yayınların katalog bilgilerinin de veri tabanına 
girilebilmesi için 2003 yılı Kasım ayında Banka dışından iki kütüphaneci geçici görevle istihdam edilmiştir. Hemen hemen tüm süreli yayınlar sisteme kaydedilmiş, böylece kitap ve süreli yayınlar tek bir veri tabanından taranabilir duruma gelmiştir. 2005 yılı sonunda süreli yayınların da kitaplarla aynı ortamdan ödünç verilmesi planlanmıştır.

Kütüphanenin katalog veri tabanı 2001 yılında satın alınan BLISS WEB modülü ile Banka içi ve Banka dışı kullanıcıların İnternet üzerinden erişimine açılmıştır.

\section{Kütüphane Web Sitesi"}

Kütüphanenin katalog kayıtlarının elektronik ortama aktarılmış olması, ilk olarak Kütüphane kayıtlarının dışa açılması gereğini ortaya çıkarmıştır. Kütüphanede yapılan hizmetlerin kullanıcılara tanıtılması ve koleksiyondaki kaynakların taranabilmesi amacıyla bir web sayfası hazırlanmış, 2001 yılında Merkez Bankası'nın web sitesinde yerini almıştır. Kütüphane web sitesinde; kütüphanenin kullanımına yönelik bilgilerin yanı sıra katalog tarama, makale tarama, basılı süreli yayınlar listesi, e-süreli yayınlar, veri tabanları başlığı altında e-veri tabanları ile CD-ROM veri tabanları, e-bilgi kaynakları, kütüphanedeki Arap harfli basma eserlerin listesi ve yeni yayınlar listesi yer almaktadır. Merkez Bankası web sitesinde yer alan TCMB yayınlarına buradan da bağlantı verilmiştir. Merkez Bankasında uzman yardımcısı olarak çalışan personelin uzman olabilmek için hazırladıkları ve kabul gören uzmanlık tezlerinin listesi de bulunmakta, tez sahibinin yazılı onay vermesi durumunda tezin tam metnine erişim de sağlanmaktadır. Kullanıcılar bu sayfada yer alan 'Danışma' ve e-posta aracılığı ile kütüphaneden bilgi almak için başvurabilmektedir (TCMB, 2005c)

\section{Sonuç}

Türkiye Cumhuriyet Merkez Bankası İdare Merkezi 1988 yılında, bugün hizmet vermekte olduğu binaya taşındığında, gerçek anlamda bir kütüphane kurulmasına önem verilmiş, bu amaçla binanın bir katı kütüphaneye ayrılmış ve 1989 yılında gerektiği kadar kütüphaneci alımı gerçekleştirilmiştir. 1997 yılına kadar kütüphaneciler belirli bir kadro unvanı ve terfi olanağı olmadan sözleşmeli olarak çalışmışlar, o tarihte çıkarılan Kütüphane Yönetmeliği ile kütüphaneci, kütüphane uzman yardımcısı ve kütüphane uzmanı kadroları oluşturulmuştur. 1989 yılında alınan kütüphanecilerle, var olan koleksiyon elden geçirilerek yeniden düzenlenirken bir yandan da hızla yeni kitap ve süreli yayınlar sağlanarak koleksiyonun hizmete uygun şekilde geliştirilme-

\footnotetext{
* Kütüphanenin web adresi: http://www.tcmb.gov.tr/kutuphane/TURKCE/indeks.htm
} 
sine çalışılmıştır. Elle yürütülen kataloglama ve ödünç verme hizmetleri, 1997 yılında BLISS-PC'nin alınmasından sonra bilgisayar aracılığıyla yürütülmeye başlanmıştır. Elektronikleşme elbette hizmetlerin daha kısa sürede ve sistemli biçimde yapılabilir, daha kolay kontrol edilebilir olmasını sağlamıştır. Kütüphane katalogunun ve diğer hizmetlerin 2001 yılında İnternet’ten erişilebilir duruma gelmesi ile elektronik veri tabanlarının sağlanmasına da başlanmış, tüm bu gelişmeler Kütüphanenin hem Banka içine hem de Banka dışına açılması, hizmetlerden daha etkin bir biçimde yararlanılması ve araşıırmacılara daha hızı ve güncel bilgi sunulabilmesi olanağını yaratıışıı.

Bugüne kadar yaptığı atıımlarla, Türkiye'de ekonomi alanında hizmet veren önemli bir kütüphane konumuna gelmiş ve bugün büyük ölçüde kurumsallaşmıştır. Bilgi Belge Müdürlüğü, Merkez Bankası yönetimince bugüne kadar olduğu gibi bundan sonra da destekleneceğine ve gelecek kütüphanecilerin de bayrak yarışı gibi, önceki yapılanları devralıp aynı hevesle geliştireceğine inanıyoruz.

\section{Kaynakça}

Kayaalp, E. (Haz.). (2001) Türkiye Cumhuriyet Merkez Bankası 2001. Ankara: TCMB.

Türkiye Cumhuriyet Merkez Bankası. (2005a). Kütüphane Yönetmeliği. (1997/. Ankara: TCMB. tcmb.gov 24 Ağustos 2005 tarihinde http://www.tcmb.gov.tr/yeni/banka/tarihce1.html adresinden erişildi.

Türkiye Cumhuriyet Merkez Bankası. (2005b). 24 Ağustos 2005 tarihinde http://www.tcmb.gov.tr/abonelik/abonelik.html adresinden erişildi.

Türkiye Cumhuriyet Merkez Bankası. (2005c). 24 Ağustos 2005 tarihinde http://www.tcmb.gov.tr/kutuphane/TURKCE/indeks.htm adresinden erişildi.

Türkiye Cumhuriyet Merkez Bankası 1932-1995. (1996). Ankara: TCMB. 